\title{
Development of a Neurosurgical Operating Table for Adult Cattle and Changes in Intracranial Pressure and Blood Pressure in Adult Cattle undergoing Long-Time Isoflurane Anesthesia
}

\author{
Shozo ARAI ${ }^{1}$, Koji YOSHIOKA ${ }^{1)}$, Chie SUZUKI ${ }^{1)}$, Hideyuki TAKAHASHI ${ }^{1)}$, Tuguo ITOH $^{2)}$ and Sadao NAKANO ${ }^{2)}$ \\ ${ }^{1)}$ Department of Production Diseases, National Institute of Animal Health, Tsukuba 305-0856 and ${ }^{2)}$ Fujihira Kohgyou, Bunkyo-ku, Tokyo \\ 113-0033, Japan
}

(Received 14 June 2005/Accepted 20 December 2005)

\begin{abstract}
We developed a neurosurgical operating table for restraining adult cattle in the sternal recumbent position during long-time inhalation anesthesia, and examined intracranial pressure (ICP), blood pressure and blood gases during isoflurane anesthesia. We confirmed that the maintenance of inhalation anesthesia, the restraint of cattle in the sternal recumbent position and bringing the cattle out of anesthesia could all be carried out safely using the operating table we produced. For the purposes of the present experiment, the cattle were divided into 2 groups: the SR group, which underwent sternal recumbency for $8 \mathrm{hr}$ under isoflurane anesthesia using the neurosurgical operating table, and the RR group, which underwent right lateral recumbency for $3 \mathrm{hr}$ under isoflurane anesthesia on a standard operating table. The mean ICP was found to be significantly lower in the SR group than in the RR group during anesthesia, and $\mathrm{PaO}_{2}$ was significantly higher in the SR group. In the SR group, no complications such as regurgitation or ruminal tympany occurred for 8 $\mathrm{hr}$ after the induction of anesthesia, and recovery from anesthesia was uneventful. In contrast, all RR cattle showed ruminal tympany and regurgitated ruminal fluid at $3 \mathrm{hr}$ after the induction of anesthesia. Thus, the neurosurgical operating table developed in the present study may be useful for long-time anesthesia and neurosurgery of adult cattle.

KEY WORDS: cattle, ICP, isoflurane, neurosurgery, operating table.
\end{abstract}

J. Vet. Med. Sci. 68(4): 337-343, 2006

Although small domestic animals such as goats and calves have been employed in neuroscientific research [7, $14,25]$, such research is rarely carried out in large domestic animals such as adult cattle since safe methods for doing so have not yet been established. Central nervous system (CNS) disease such as hydrocephalus, intraorbital lymphoma and intraorbital abscess is reported in cattle [23]. These CNS diseases may require neurosurgical correction for functional recovery. In order to perform neurosurgery of cattle, inhalation anesthesia must be maintained for long periods of time [4]. In adult cattle, inhalation anesthesia is generally carried out in the lateral recumbent or dorsal recumbent position. When the posture of the animal is changed from the standing position to the lateral or dorsal recumbent position, heart rate, respiratory rate and plasma cortisol levels increase, while $\mathrm{PaO}_{2}$ decreases [9, 20, 21]. In addition, general anesthesia and recumbency in cattle cause complications such as regurgitation and ruminal tympany. Therefore, in adult cattle, it is difficult to maintain inhalation anesthesia for long periods of time in the lateral recumbent or dorsal recumbent position. Furthermore, it is important to monitor and control intracranial pressure (ICP) during neurosurgery, but very little research has been conducted on changes in ICP in cattle [2].

The purposes of this study were to develop a neurosurgical operating table for restraining adult cattle in the sternal recumbent position during long-time inhalation anesthesia, and to examine ICP, blood pressure and blood gases in isoflurane-anesthetized adult cattle.

\section{MATERIALS AND METHODS}

Development of a neurosurgical operating table: We developed a neurosurgical operating table for restraining adult cattle in the sternal recumbent position (Fig. 1). The size of the table is $150 \mathrm{~cm}$ in width, $463 \mathrm{~cm}$ in length and $230 \mathrm{~cm}$ height, with a weight of 2 tons. The frame of the table is made of stainless steel. The main body of the operating table can be raised to $950 \mathrm{~cm}$ by pressure lift, and the head lift can be raised to $40 \mathrm{~cm}$. The position of the table is manipulated by a control panel $(200 \mathrm{~V})$. The operating table consists of an air bag restraint system, a lift for fixing the position of the lumbar region of the animal, an alarm device, a wide frame, a screen to prevent excessive motion and an emergency shutdown lever. The surface of the operating table is covered with natural rubber.

Animals: Six healthy Holstein cows weighing 425 to 625 $\mathrm{kg}$ were used in the present experiment. The animals were housed in individual stanchion stalls, and were given a commercial cattle concentrate, hay and free access to water. The handling of all animals used in this experiment was approved by the Institutional Care and Use Committee for Laboratory Animals of the National Institute of Animal Health.

Catheterization for measurement of ICP and arterial blood pressure: Food and water were withheld for $24 \mathrm{hr}$ prior to anesthesia. After the cattle were guided to the neurosurgical operating table, a stanchion was installed at the head of the cattle. Each animal was premedicated intramuscularly with atropine sulfate $(0.03 \mathrm{mg} / \mathrm{kg}$; Fuso Pharmaceu- 
tical Industries, Ltd, Osaka, Japan). After 10 min, anesthesia was induced by intravenous infusion of ketamine hydrochloride ( $2 \mathrm{mg} / \mathrm{kg}$; Sankyo Co., Tokyo, Japan) and xylazine hydrochloride $(0.2 \mathrm{mg} / \mathrm{kg}$; Bayer, Leverkusen, Germany). The cattle were placed in the sternal recumbent position using the air bag on the operating table, a large animal endotracheal tube was inserted and connected to the anesthesia apparatus of a semi-closed circle system (Senko Medical Instruments, Tokyo, Japan), and anesthesia was induced with isoflurane (Dainippon Pharmaceutical, Osaka, Japan), oxygen and nitrous oxide. The operating table was raised to the appropriate level for efficient operation, and the head lift was raised an additional $30 \mathrm{~cm}$ to prevent regurgitation of ruminal fluid (Fig. 1B).

Skin and muscle were retracted to expose the frontal bone. The frontal bone and sinus cavity were removed using a Neuroairtome Drill (3 M Health Care, St. Paul, MN, U.S.A.) to drill a hole $2 \times 2.5 \mathrm{~cm}$ at the appropriate places to expose the dura mater. A catheter for ICP measurement (ICP Monitoring Kit, TM-200T, Nihon Kohden, Tokyo, Japan) was carefully inserted, using a spatula to separate the skull and the dura mater. The dura mater was covered with a gelatin sponge (Yamanouchi Pharmaceutical, Tokyo, Japan), and the catheter was fixed to the frontal bone with acrylic dental cement (GC, Tokyo, Japan), after shaping it to the position required based on the removed skull. Next, the ICP catheter was positioned in a fabric bag $(13 \times 10 \mathrm{~cm})$ installed in the occiput, using a hypodermic needle to assist in placement.

Following the installation of the ICP catheter, further catheterization was performed by insertion of an 18-gauge catheter (Medicut UK-II Catheter Kit, Unitika, Hyogo, Japan) $55 \mathrm{~cm}$ into the left femoral artery.

After the cattle were sedated intramuscularly with xylazine hydrochloride $(0.05 \mathrm{mg} / \mathrm{kg}$; Bayer $)$, the anesthetic circuit was disconnected. The endotracheal tube was removed immediately once swallowing was observed. The cattle were injected intramuscularly with antibiotics (Doupen, 10 $\mathrm{mg} / \mathrm{kg}$, Tanabe Seiyaku, Osaka, Japan) prior to sugery and for 3 days after surgery. The cattle were returned to their stalls 2 to $3 \mathrm{hr}$ after anesthesia.

Experimental procedure: The experiment was carried out using cattle at a minimum of 14 days after surgery. The animals for the experiment were divided into two groups: the SR group $(n=3)$ underwent sternal recumbency for $8 \mathrm{hr}$ under isoflurane anesthesia using our neurosurgical operating table, and the RR group $(n=3)$ underwent right lateral recumbency for $3 \mathrm{hr}$ under isoflurane anesthesia using a standard operating table. Food and water were withheld for $24 \mathrm{hr}$ prior to anesthesia in each group.

For the SR group, the cattle were guided to the neurosurgical operating table, where they were administered an intravenous infusion of ketamine hydrochloride $(2 \mathrm{mg} / \mathrm{kg})$ and xylazine hydrochloride $(0.2 \mathrm{mg} / \mathrm{kg})$, and an intramuscularly infusion of atropine sulfate $(0.03 \mathrm{mg} / \mathrm{kg})$. The cattle were placed in the sternal recumbent position, an endotracheal tube was inserted, and anesthesia was induced with isoflurane, oxygen and nitrous oxide. The vaporizer settings were 3 to $4 \%$ during the first $10 \mathrm{~min}$ and were then maintained at $2.5 \%$. The oxygen flow rate was $3 \mathrm{l} / \mathrm{min}$ and the nitrous oxide flow rate was $1.5 \mathrm{l} / \mathrm{min}$. The head lift of the operating table was raised to $30 \mathrm{~cm}$ to prevent regurgitation of ruminal fluid. The duration of anesthesia was $480 \mathrm{~min}$.

For the RR group, the cattle were guided to the operating table (Fujihira Kogyo Co., Tokyo, Japan), where they were placed in the right lateral recumbent position. They were administered an intravenous infusion of ketamine hydrochloride $(2 \mathrm{mg} / \mathrm{kg})$ and xylazine hydrochloride $(0.2 \mathrm{mg} / \mathrm{kg})$, and an intramuscularly infusion of atropine sulfate $(0.03$ $\mathrm{mg} / \mathrm{kg}$ ). An endotracheal tube was inserted, and anesthesia was induced with isoflurane, oxygen and nitrous oxide. The vaporizer settings were 3 to $4 \%$ during the first $10 \mathrm{~min}$ and were then maintained at $2.5 \%$. The oxygen flow rate was 3 $\mathrm{l} / \mathrm{min}$ and the nitrous oxide flow rate was $1.5 \mathrm{l} / \mathrm{min}$. The duration of anesthesia was $180 \mathrm{~min}$.

In both groups, after the period of anesthesia ended, the anesthetic circuit was disconnected. The endotracheal tube was removed as soon as swallowing was observed. Two to $3 \mathrm{hr}$ after anesthesia, all cattle were returned to their stalls.

Measurements: Rectal temperature $\left({ }^{\circ} \mathrm{C}\right)$, heart rate (beats/ $\mathrm{min})$, respiratory rate (breaths/min), blood glucose concentrations $(\mathrm{mg} / \mathrm{d} l)$, arterial blood $\mathrm{pH}(\mathrm{pHa})$, arterial carbon dioxide tension $\left(\mathrm{PaCO}_{2} ; \mathrm{mmHg}\right)$, arterial oxygen tension $\left(\mathrm{PaO}_{2} ; \mathrm{mmHg}\right), \mathrm{ICP}(\mathrm{mmHg})$ and arterial blood pressure $(\mathrm{mmHg})$ were determined during anesthesia in all cattle.

An electrocardiogram (ECG) was recorded using AB leads. Respiratory rate was measured based on the movements of the thorax (TSD201, Biopac Systems, Inc., CA, U.S.A.). Systolic, mean and diastolic arterial blood pressures (SAP, MAP, and DAP, respectively) were measured by connecting the catheter which had been placed in the left femoral artery to a pressure transducer (TP-400T, Nihon Kohden), and maximum, mean and minimum ICPs were measured by connecting the catheter which had been placed on the dura mater to a pressure transducer (TP-400T, Nihon Kohden). The recording and analysis of ECG, respiratory rate, arterial blood pressure and ICP were carried out using a monitoring system (MP-100WS, Biopac). To measure ICP, the pressure transducer was positioned at the level of the brain, while to measure arterial blood pressure, the pressure transducer was positioned at the level of the heart.

Arterial blood was anaerobically collected from the catheter in the left femoral artery with a heparinized syringe. Arterial blood $\mathrm{pH}, \mathrm{PaCO}_{2}$ and $\mathrm{PaO}_{2}$ were immediately measured with a blood gas analyzer (IL1360, Instrumentation Laboratory, Milan, Italy).

To measure blood glucose levels, blood was collected via a catheter in the jugular vein. Whole blood was transferred to a test tube containing sodium fluoride, and glucose concentrations were then measured using a blood glucose test meter (GT-1640, Arkray Inc., Kyoto, Japan).

Baseline cardiopulmonary data (pre-data) such as rectal temperature, heart rate, respiratory rate, blood glucose, $\mathrm{pHa}$, $\mathrm{PaCO}_{2}, \mathrm{PaO}_{2}$, ICP and arterial blood pressure were recorded 

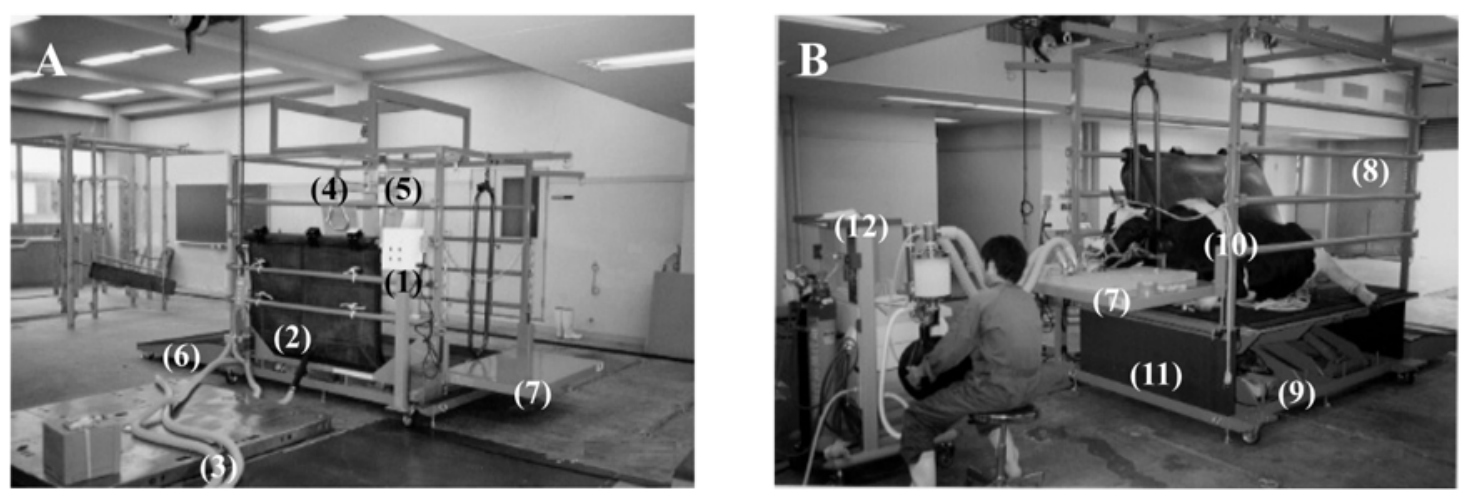

Fig. 1. A: Neurosurgical operating table for adult cattle. B: Anesthesia in the sternal recumbent position. (1) Control panel. (2) Air bag restraint system. (3) Air supply tube and air inlet tube. (4) Lift for fixing the position of the lumber region of cattle. (5) Alarm device. (6) Footstool. (7) Head lift. (8) Wide frame. (9) Pressure lift. (10) Prop for fixing the head. (11) Preventive screen. (12) Anesthesia apparatus.

in all cattle in the standing position prior to medication. In both groups, cardiopulmonary measurements were recorded every 30 min throughout the period of anesthesia.

Statistical analysis: Data are expressed as the mean \pm standard deviation. Statistical analysis was carried out by Student's $t$-test to identify significant differences between the $\mathrm{SR}$ and RR groups. Differences were considered significant at $\mathrm{p}<0.05$.

\section{RESULTS}

Manipulation of the neurosurgical operating table: The present study confirmed that the introduction of cattle to our neurosurgical operating table, the maintenance of inhalation anesthesia, restraint of the animals in the sternal recumbent position, and bringing the cattle out of anesthesia could all be safely carried out on our experimental table (Fig. 1B).

Clinical signs of cattle during anesthesia: The induction of and recovery from anesthesia was uneventful in all SR cattle. In this group, no complications such as regurgitation or ruminal tympany were observed during the entire 480 $\mathrm{min}$ of anesthesia. In contrast, all cattle of the RR group suffered ruminal tympany and regurgitated ruminal fluid at 180 min after the induction of anesthesia. Therefore, it was not possible to maintain anesthesia in this RR group. All cattle of both groups were able to stand up within $1 \mathrm{hr}$ after the end of anesthesia, and normally walked within $2 \mathrm{hr}$.

Changes in ICP and arterial blood pressure: In the standing position prior to medication, the mean ICPs of the SR and RR groups were $5.3 \pm 2.2 \mathrm{mmHg}$ and $6.9 \pm 3.3 \mathrm{mmHg}$, respectively (Fig. 2). The mean ICP of the SR group increased slightly at 15 and $60 \mathrm{~min}$ of maintenance anesthesia, and then remained constant at approximately $7 \mathrm{mmHg}$ from 90 to $480 \mathrm{~min}$ after the induction of anesthesia. The mean ICP of the RR group increased after the induction of anesthesia, reaching $15.4 \pm 0.2 \mathrm{mmHg}$ at $60 \mathrm{~min}$ of maintenance anesthesia. The mean ICP was significantly lower in the SR group than in the RR group at 30,120 and $150 \mathrm{~min}$

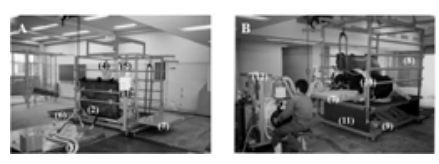

Fig. 2. Changes in mean intracranial pressure and mean arterial blood pressure in the two groups. Data are expressed as mean \pm standard deviation. Significant differences were observed between cattle in right lateral recumbency and those in sternal recumbency $(* P<0.05, * * P<0.01)$.

(Fig. 2). Additionally, the maximum and minimum ICPs were significantly lower in the SR group at 30,120 and 150 $\min$ (Table 1). In the standing position prior to medication, the MAPs of the SR and RR groups were $127 \pm 6.2 \mathrm{mmHg}$ and $133.4 \pm 0.7 \mathrm{mmHg}$, respectively. The MAPs of both groups decreased in the first 30 to 60 min following anesthesia, and then increased at 120 to $150 \mathrm{~min}$ of maintenance anesthesia. There were no significant differences in MAP, SAP or DAP between groups (Table 1 and Fig. 2), however, all three measurements of the SR group tended to be lower 
Table 1. Changes in systolic arterial blood pressure, diastolic arterial blood pressure, maximum intracranial pressure, and minimum intracranial pressure in cattle anesthetized with isoflurane in sternal recumbency and right lateral recumbency

\begin{tabular}{|c|c|c|c|c|c|c|c|c|}
\hline \multirow{2}{*}{$\begin{array}{l}\text { Time of } \\
\text { anesthesia }\end{array}$} & \multicolumn{2}{|c|}{$\mathrm{SAP}(\mathrm{mmHg})$} & \multicolumn{2}{|c|}{$\mathrm{DAP}(\mathrm{mmHg})$} & \multicolumn{2}{|c|}{ Max ICP (mmHg) } & \multicolumn{2}{|c|}{ Min ICP $(\mathrm{mmHg})$} \\
\hline & SR & $\mathrm{RR}$ & SR & $\mathrm{RR}$ & SR & $\mathrm{RR}$ & SR & $\mathrm{RR}$ \\
\hline Pre & $159.7 \pm 11.3$ & $167.0 \pm 5.7$ & $96.7 \pm 8.6$ & $102.2 \pm 8.3$ & $7.4 \pm 3.8$ & $12.2 \pm 3.8$ & $3.5 \pm 1.1$ & $3.8 \pm 3.2$ \\
\hline $15 \mathrm{~min}$ & $138.7 \pm 13.6$ & $146.5 \pm 45.9$ & $92.7 \pm 8.0$ & $101.2 \pm 43.6$ & $11.5 \pm 7.4$ & $10.5 \pm 3.9$ & $7.8 \pm 5.4$ & $6.4 \pm 3.9$ \\
\hline $30 \mathrm{~min}$ & $111.0 \pm 19.1$ & $141.0 \pm 55.2$ & $69.7 \pm 15.0$ & $99.7 \pm 49.9$ & $8.1 \pm 3.5^{*}$ & $16.6 \pm 1.9^{*}$ & $4.7 \pm 3.4^{*}$ & $10.3 \pm 1.9 *$ \\
\hline $60 \mathrm{~min}$ & $127.3 \pm 35.8$ & $133.0 \pm 21.0$ & $89.3 \pm 30.6$ & $91.0 \pm 15.4$ & $11.6 \pm 7.3$ & $17.9 \pm 0.1$ & $8.4 \pm 6.5$ & $12.5 \pm 1.2$ \\
\hline $90 \mathrm{~min}$ & $152.0 \pm 19.1$ & $143.0 \pm 18.4$ & $110.3 \pm 19.1$ & $108.0 \pm 18.9$ & $8.8 \pm 4.1$ & $16.0 \pm 1.5$ & $6.1 \pm 2.9$ & $10.9 \pm 1.5$ \\
\hline $120 \mathrm{~min}$ & $165.7 \pm 10.8$ & $187.5 \pm 43.1$ & $125.3 \pm 3.1$ & $141.0 \pm 31.1$ & $7.9 \pm 4.6^{*}$ & $16.2 \pm 1.7^{*}$ & $5.6 \pm 3.2^{*}$ & $9.9 \pm 1.6^{*}$ \\
\hline $150 \mathrm{~min}$ & $171.7 \pm 20.6$ & $190.5 \pm 30.4$ & $129.0 \pm 14.0$ & $143.5 \pm 19.1$ & $9.3 \pm 2.7 * *$ & $17.6 \pm 2.3 * *$ & $6.5 \pm 1.6^{* *}$ & $12.7 \pm 0.6^{* *}$ \\
\hline $180 \mathrm{~min}$ & $174.3 \pm 14.6$ & $184.5 \pm 30.4$ & $131.7 \pm 5.0$ & $140.0 \pm 18.4$ & $8.5 \pm 3.6$ & $18.2 \pm 5.9$ & $5.8 \pm 2.2$ & $12.1 \pm 3.5$ \\
\hline $210 \mathrm{~min}$ & $176.0 \pm 19.3$ & NT & $133.7 \pm 11.0$ & NT & $8.0 \pm 2.4$ & NT & $5.5 \pm 1.5$ & NT \\
\hline $240 \mathrm{~min}$ & $173.3 \pm 18.7$ & NT & $133.0 \pm 12.3$ & NT & $7.4 \pm 1.9$ & NT & $4.9 \pm 0.8$ & NT \\
\hline $270 \mathrm{~min}$ & $163.7 \pm 17.0$ & NT & $127.7 \pm 15.3$ & NT & $7.7 \pm 2.6$ & NT & $5.7 \pm 2.4$ & NT \\
\hline $300 \mathrm{~min}$ & $170.3 \pm 18.5$ & NT & $135.3 \pm 14.2$ & NT & $7.8 \pm 2.7$ & NT & $5.9 \pm 2.4$ & NT \\
\hline $330 \mathrm{~min}$ & $157.3 \pm 15.4$ & NT & $120.3 \pm 11.9$ & NT & $7.9 \pm 2.7$ & NT & $5.9 \pm 2.4$ & NT \\
\hline $360 \mathrm{~min}$ & $168.0 \pm 19.7$ & NT & $130.3 \pm 15.5$ & NT & $7.9 \pm 2.7$ & NT & $6.0 \pm 2.4$ & NT \\
\hline $390 \mathrm{~min}$ & $159.0 \pm 4.2$ & NT & $121.0 \pm 1.41$ & NT & $8.0 \pm 3.3$ & NT & $5.7 \pm 3.0$ & NT \\
\hline $420 \mathrm{~min}$ & $166.0 \pm 18.4$ & NT & $124.7 \pm 21.5$ & NT & $9.3 \pm 4.0$ & NT & $6.3 \pm 2.7$ & NT \\
\hline $450 \mathrm{~min}$ & $170.7 \pm 12.0$ & NT & $124.7 \pm 4.9$ & NT & $9.6 \pm 4.3$ & NT & $6.3 \pm 2.7$ & NT \\
\hline $480 \mathrm{~min}$ & $188.7 \pm 19.2$ & NT & $141.3 \pm 17.0$ & NT & $9.4 \pm 3.9$ & NT & $6.3 \pm 2.6$ & NT \\
\hline
\end{tabular}

Data are expressed as mean \pm standard deviation. Significant differences between the SR and RR $(* P<0.05, * P<0.01)$. SR: Sternal recumbency, RR: Right lateral recumbency, SAP: Systolic arterial blood pressure, DAP: Diastolic arterial blood pressure, Max ICP: Maximum intracranial pressure, Min ICP: Minimum intracranial pressure, NT: Not tested.

than those of the RR group during anesthesia.

Changes in arterial blood gases: The $\mathrm{PaO}_{2}$ levels of the $\mathrm{SR}$ and RR groups were increased at $296.7 \pm 53 \mathrm{mmHg}$ and $236 \pm 11.3 \mathrm{mmHg}$, respectively, until $15 \mathrm{~min}$ after anesthesia, after which point the $\mathrm{PaO}_{2}$ levels of the SR group remained higher than those of RR group during anesthesia (Fig. 3). $\mathrm{PaO}_{2}$ was significantly higher in the $\mathrm{SR}$ group at 150 and 180 min after the induction of anesthesia $(\mathrm{P}<0.05)$. There were no significant differences in arterial blood $\mathrm{pH}$ or $\mathrm{PaCO}_{2}$ between the two groups at any time during anesthesia (Fig. 3).

Changes in rectal temperature, heart rate, respiratory rate and blood glucose concentrations: There were no significant differences in rectal temperature, heart rate, respiratory rate and blood glucose concentrations between SR and RR groups at any time during anesthesia (Table 2).

\section{DISCUSSION}

In the present study, we found that our neurosurgical operating table made it possible to place adult cattle in the sternal recumbent position and to safely maintain inhalation anesthesia with isoflurane for at least $8 \mathrm{hr}$. When the posture of cattle is changed from the standing position to the lateral or dorsal recumbent position, heart rate, respiratory rate and plasma cortisol levels increase, while $\mathrm{PaO}_{2}$ decreases $[9,20,21]$. In addition, general anesthesia and recumbency cause complications such as regurgitation, ruminal tympany and myositis in cattle [16]. Because of these complications, it is difficult to maintain inhalation anesthesia for long periods of time. In the present study, because all cattle of the RR group were observed to suffer ruminal tympany and regurgitated ruminal fluid at $3 \mathrm{hr}$ after the induction of anesthesia, it was impossible to maintain anesthesia. When anesthetizing cattle, the positioning of the animal presents problems related to both size and anatomy. Ventilation is markedly compromised in dorsal recumbency due to the weight of the animal and pressure from the abdominal organs on the diaphragm. Rugh et al. report that, because ventilatory efficiency is best in the sternal position, cattle should be rolled to sternal recumbency immediately upon completion of surgery [16]. In the present study, cattle were placed in the sternal recumbent position using an air bag on the operating table, and their heads were further raised to 30 $\mathrm{cm}$ by the head lift during anesthesia. Because this posture facilitates the dissipation of excessive ruminal gases which may accumulate during anesthesia, no SR cattle in the present study suffered ruminal tympany, regurgitation or myositis during their $8 \mathrm{hr}$ of anesthesia.

The CNS disease such as hydrocephalus, intraorbital lymphoma and intraorbital abscess is reported in cattle [23], and these CNS diseases may require neurosurgical correction for functional recovery. The monitor and control of ICP with neurosurgery is carried out in human, dog and cat $[1,5,19]$, and it is important for the management of brain edema and hemorrhage $[19,24]$. However, in cattle, very little research has been conducted on changes in ICP [2]. It is important to maintain a low ICP during neurosurgery in order to prevent cerebral hemorrhage [22]. In the present study, the ICPs of cattle in the sternal recumbent position were significantly lower than those of cattle in the lateral recumbent position during anesthesia. Changes in posture are known to affect the ICPs of humans and dogs [3, 12, 13, 18]. Shah reports that the extradural pressure was greatest 


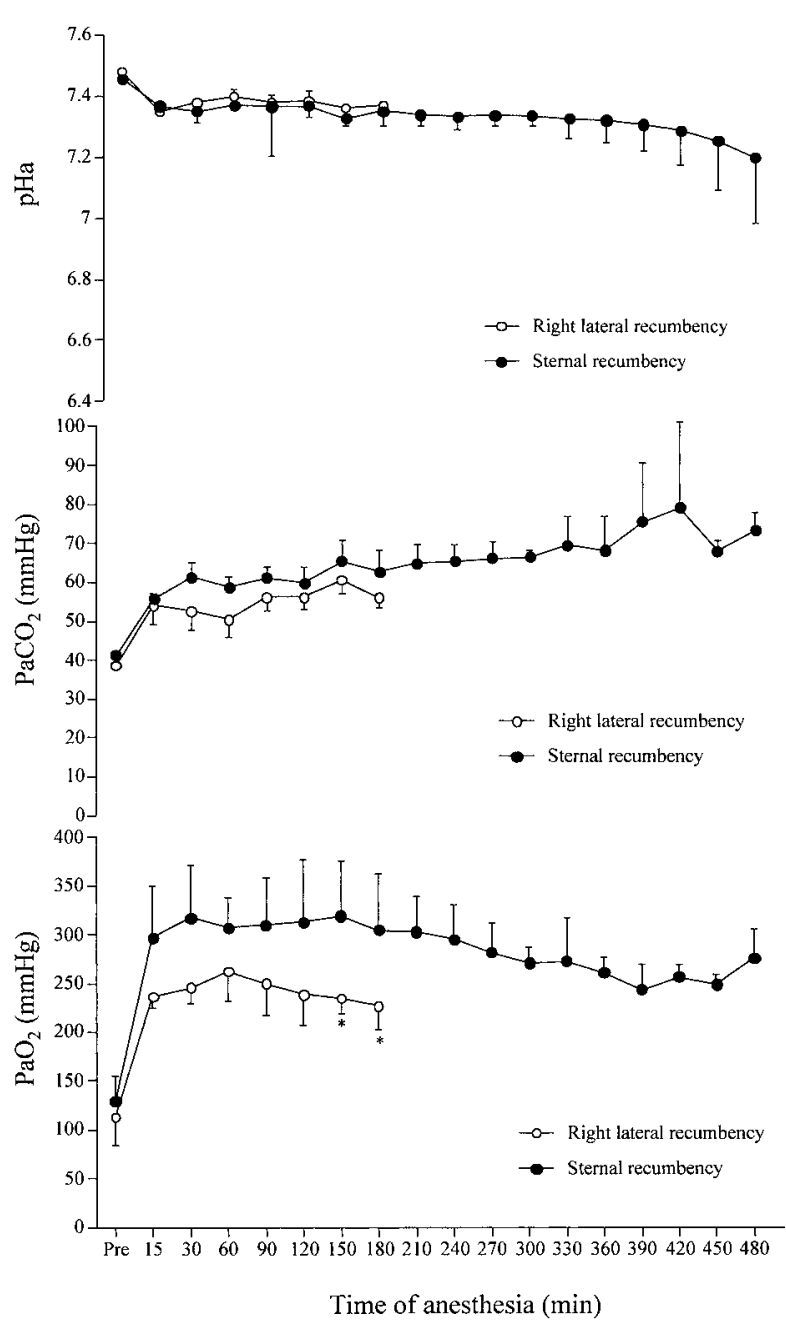

Fig. 3. Changes in arterial blood $\mathrm{pH}(\mathrm{pHa})$, arterial carbon dioxide tension $\left(\mathrm{PaCO}_{2}\right)$ and arterial oxygen tension $\left(\mathrm{PaO}_{2}\right)$ in cattle anesthetized with isoflurane in right lateral recumbency and sternal recumbency. Data are expressed as mean \pm standard deviation. *Significant differences were observed between cattle in right lateral recumbency and those in sternal recumbency $(P<0.05)$.

in the supine position and least in the prone position in human patients, the mean pressure being 22.6, 14.8 and 2.2 $\mathrm{cmH}_{2} \mathrm{O}$ in the supine, lateral and prone positions, respectively [18]. Changes in extradural pressure probably result from changes in cerebrospinal fluid (CSF) pressure caused by alterations in blood volume within the extradural space [18]. Changes in CSF pressure are associated with changes in cerebral blood volume [3]. In the present study, the increase in ICP in the lateral recumbent position may be caused by an increase in cerebral blood volume with changes in posture.

Changes in head position are known to affect ICP and cerebral blood volume in humans and cats $[10,12]$. In anesthetized human patients, differences have been observed between head-up and head-down tilt, specifically, cerebral blood volume was found to decrease with an $18^{\circ}$ head-up tilt and increase with an $18^{\circ}$ head-up tilt [12]. The ICP of cats was found to have increased significantly at $10 \mathrm{~min}$ in the head-down tilt position as compared with a control position [10]. In the present study, the ICP of SR cattle in a $30 \mathrm{~cm}$ head-up position was lower than that of RR cattle without the head-up position. Lovell et al. report that the reduction in cerebral blood volume might be caused by a reduction in the volume of the venous and/or capillary compartments; they also suggest that changes in cerebral blood volume are unlikely to be the result of an increase in the arterial compartment, because arterial blood pressure did not change during tilting in their experiments [12]. In the present study, we observed similar results in the changing ICPs of cattle depending on head position, but arterial blood pressure showed no significant changes between the two tested groups.

Hypertension has been shown in adult cattle anesthetized with halothane, isoflurane or sevoflurane $[6,8,17]$. This hypertension is associated with a decrease in cardiac output and an increase in heart rate and total vascular resistance [17]. In the present study, hypertension was recorded from $120 \mathrm{~min}$ after the induction of anesthesia, compared with premedication measurements. We observed results similar to those previously reported, such as an increase in heart rate in both groups after the induction of anesthesia with isoflurane. On the other hand, MAP and heart rate were decreased from 15 to $60 \mathrm{~min}$ after the induction of anesthesia with xylazine-ketamine-isoflurane in both groups in this study. This decrease in MAP and heart rate are probably attributable to a characteristic response to the injection of xylazine. Although MAP did not change significantly in isofluraneanesthetized cattle, the administration of a xylazine-ketamine drug combination to calves has been found to produce immediate decreases in MAP, heart rate and cardiac output $[6,15]$. A decrease in MAP after the injection of xylazine may be attributed to bradycardia as a result of CNS depression and vasodilation $[11,15]$.

In the present study, $\mathrm{PaO}_{2}$ levels in the SR group were higher than those in the RR group during anesthesia. One factor contributing to decreased $\mathrm{PaO}_{2}$ in the lateral recumbent position is reduced functional residual capacity with displacement of the diaphragm by the abdominal viscera, or the elimination of ventilation in the lung by compression of the diaphragmatic portions of the lungs [20]. In anesthetized horses, lateral or dorsal recumbency results in a decrease in functional residual capacity, vital capacity and residual volume [20].

In the present study, we observed that arterial $\mathrm{pH}$ decreased slightly with time, indicating the development of metabolic acidosis, possibly as a result of an increase in $\mathrm{PaCO}_{2}$. Specifically, $\mathrm{PaCO}_{2}$ levels in the SR group tended to increase from 300 to $480 \mathrm{~min}$ after the induction of anesthesia, possibly due to the lower absorption capacity of carbon dioxide in an absorber whose efficiency has been reduced by long-time anesthesia. 
Table 2. Changes in rectal temperature, heart rate, respiratory rate and blood glucose concentrations in cattle anesthetized with isoflurane in sternal recumbency and right lateral recumbency

\begin{tabular}{|c|c|c|c|c|c|c|c|c|}
\hline \multirow{2}{*}{$\begin{array}{l}\text { Time of } \\
\text { anesthesia }\end{array}$} & \multicolumn{2}{|c|}{ Rectal temperature $\left({ }^{\circ} \mathrm{C}\right)$} & \multicolumn{2}{|c|}{ Heart rate (beats/min) } & \multicolumn{2}{|c|}{ Respiratory rate (breaths/min) } & \multicolumn{2}{|c|}{ Glucose $(\mathrm{mg} / \mathrm{d} l)$} \\
\hline & SR & $\mathrm{RR}$ & SR & $\mathrm{RR}$ & SR & $\mathrm{RR}$ & SR & $\mathrm{RR}$ \\
\hline Pre & $38.5 \pm 0.3$ & $38.6 \pm 0.2$ & $68.3 \pm 3.2$ & $56.5 \pm 20.5$ & $21.3 \pm 4.6$ & $32.5 \pm 15.0$ & $50 \pm 8.9$ & $50 \pm 5.7$ \\
\hline $15 \mathrm{~min}$ & $38.8 \pm 0.4$ & $39.0 \pm 0.6$ & $65.3 \pm 9.7$ & $66.0 \pm 1.4$ & $52.0 \pm 13.9$ & $30.0 \pm 16.9$ & $120 \pm 9.8$ & $142 \pm 27.6$ \\
\hline $30 \mathrm{~min}$ & $38.7 \pm 0.2$ & $38.9 \pm 0.7$ & $71.7 \pm 0.6$ & $66.0 \pm 4.2$ & $58.0 \pm 3.5$ & $33.0 \pm 21.2$ & $138 \pm 5.5$ & $150 \pm 46.7$ \\
\hline $60 \mathrm{~min}$ & $38.6 \pm 0.3$ & $38.7 \pm 0.7$ & $72.0 \pm 0$ & $64.5 \pm 10.6$ & $55.3 \pm 4.2$ & $39.0 \pm 4.2$ & $147 \pm 18.1$ & $146 \pm 38.8$ \\
\hline $90 \mathrm{~min}$ & $38.4 \pm 0.2$ & $38.3 \pm 0.8$ & $66.3 \pm 6.0$ & $66.0 \pm 15.6$ & $50.7 \pm 2.3$ & $37.5 \pm 6.4$ & $153 \pm 9.5$ & $142 \pm 28.3$ \\
\hline $120 \mathrm{~min}$ & $38.0 \pm 0.4$ & $38.2 \pm 0.6$ & $68.0 \pm 3.5$ & $65.5 \pm 12.1$ & $49.3 \pm 2.3$ & $39.0 \pm 4.2$ & $151 \pm 19.3$ & $139 \pm 18.4$ \\
\hline $150 \mathrm{~min}$ & $37.9 \pm 0.1$ & $38.3 \pm 0.4$ & $67.3 \pm 4.2$ & $73.0 \pm 18.4$ & $46.7 \pm 5.0$ & $36.0 \pm 8.5$ & $162 \pm 17.6$ & $141 \pm 28.3$ \\
\hline $180 \mathrm{~min}$ & $37.8 \pm 0.1$ & $38.5 \pm 0.4$ & $69.0 \pm 13.1$ & $73.5 \pm 20.5$ & $47.3 \pm 5.1$ & $33.0 \pm 12.7$ & $162 \pm 14$ & $135 \pm 26.9$ \\
\hline $210 \mathrm{~min}$ & $37.8 \pm 0.1$ & NT & $71.0 \pm 11.3$ & NT & $42.7 \pm 1.2$ & NT & $165 \pm 26.1$ & NT \\
\hline $240 \mathrm{~min}$ & $37.9 \pm 0.3$ & NT & $80.7 \pm 24.2$ & NT & $40.0 \pm 4.0$ & NT & $151 \pm 34$ & NT \\
\hline $270 \mathrm{~min}$ & $38.0 \pm 0.3$ & NT & $78.3 \pm 17.5$ & NT & $38.7 \pm 2.3$ & NT & $141 \pm 30.5$ & NT \\
\hline $300 \mathrm{~min}$ & $38.0 \pm 0.3$ & NT & $86.0 \pm 34.3$ & NT & $36.7 \pm 5.0$ & NT & $132 \pm 24.5$ & NT \\
\hline $330 \mathrm{~min}$ & $38.1 \pm 0.5$ & NT & $81.7 \pm 33.4$ & NT & $38.7 \pm 2.3$ & NT & $120 \pm 30.8$ & NT \\
\hline $360 \mathrm{~min}$ & $37.9 \pm 0.3$ & NT & $87.7 \pm 30.7$ & NT & $32.7 \pm 3.1$ & NT & $116 \pm 37.6$ & NT \\
\hline $390 \mathrm{~min}$ & $38.1 \pm 0.5$ & NT & $72.0 \pm 12.0$ & NT & $36.7 \pm 7.0$ & NT & $117 \pm 27.8$ & NT \\
\hline $420 \mathrm{~min}$ & $38.0 \pm 0.5$ & NT & $89.0 \pm 23.3$ & NT & $34.7 \pm 6.4$ & NT & $118 \pm 36$ & NT \\
\hline $450 \mathrm{~min}$ & $37.9 \pm 0.4$ & NT & $71.5 \pm 9.2$ & NT & $31.3 \pm 4.2$ & NT & $109 \pm 26.2$ & NT \\
\hline $480 \mathrm{~min}$ & $37.6 \pm 0.3$ & NT & $81.5 \pm 20.5$ & NT & $28.0 \pm 4.0$ & NT & $107 \pm 32.2$ & NT \\
\hline
\end{tabular}

Data are expressed as mean \pm standard deviation. There are no significant differences between the SR and RR. SR: Sternal recumbency, RR: Right lateral recumbency, NT: Not tested.

All SR cattle in the present study recovered from anesthesia without complications. In addition, all cattle were able to stand up within $1 \mathrm{hr}$ after the end of anesthesia, and walked within $2 \mathrm{hr}$. In cattle, the time to standing position and walking from the end of sevoflurane anesthesia for 75 min has been found to be $16 \mathrm{~min}$ and $2 \mathrm{hr}$, respectively [8].

The present findings suggest that in the case of long-time anesthesia in cattle, the sternal recumbency with a head-up position makes it possible to maintain lower ICP levels and to prevent complications. The neurosurgical operating table developed in the present study may thus be useful for longtime anesthesia and neurosurgery in adult cattle.

\section{REFERENCES}

1. Bagley, R. S., Harrington, M. L., Gavin, P. R. and Moore, M. P. 1997. Acute, unilateral transverse sinus occlusion during craniectomy in seven dogs with space-occupying intracranial disease. Vet. Surg. 26: 195-201.

2. Donoghue, S., Frier, H. I., Eaton, H. D. and Lucas, J. J. 1972. Lateral ventricular cerebrospinal fluid pressure of Holstein male calves measured in a sternal recumbent position under general anesthesia. J. Dairy Sci. 55: 1636-1638.

3. Ernst, P. S., Albin, M. S. and Bunegin, L. 1990. Intracranial and spinal cord hemodynamics in the sitting position in dogs in the presence and absence of increased intracranial pressure. Anesth. Analg. 70: 147-153.

4. Frier H. I., Gallina, A. M., Rousseau, J. E. and Eaton, H. D. 1972. Rates of formation and absorption of cerebrospinal fluid in the very young calf. J. Dairy Sci. 55: 339-344.

5. Gaab, M., Knoblich, O. E., Fuhrmeister, U., Pflughaupt, K. W. and Dietrich, K. 1979. Comparison of the effects of surgical decompression and resection of local edema in the therapy of experimental brain trauma. Investigation of ICP, EEG and cerebral metabolism in cats. Childs. Brain. 5: 484-498.
6. Greene, S. A., Tyner, C. L., Morris, D. L. and Hartsfield, S. M. 1988. Comparison of cardiopulmonary effects of isoflurane and halothane after atropine-guaifenesin-thiamylal anesthesia for rumenotomy in steers. Am. J. Vet. Res. 49: 1891-1893.

7. Hedlund, L., Lischko, M. M. and Garner, H. E. 1976. Cerebral ventricle cannulation in the calf. J. Dairy Sci. 60: 997-1000.

8. Hikasa, Y., Takase, K., Kondou, K. and Ogasawara, S. 1994. Sevoflurane anesthesia following administration of atropineguaifenesin-thiopental in spontaneous-breathing adult cattle. $J$. Vet. Med. Sci. 56: 613-616.

9. Klein, L. and Fisher, N. 1988. Cardiopulmonary effects of restraint in dorsal recumbency on awake cattle. Am. J. Vet. Res. 49: $1605-1608$

10. Kotani, J., Momota, Y., Sugioka, S., Umemura, A. and Ueda, Y. 1993. Effect of head-down tilt on intracranial pressure and sagittal sinus pressure during general anesthesia in cats. Anesth. Prog. 39: 209-211.

11. Lin, H. C., Thurmon, J. C., Tranquilli, W. J., Benson, G. J. and Olson, W. A. 1991. Hemodynamic response of calves to tiletamine-zolazepam-xylazine anesthesia. Am. J. Vet. Res. 52: $1606-1610$

12. Lovell, A. T., Marshall, A. C., Elwell, C. E., Smith, M. and Goldstone, J. C. 2000. Changes in cerebral blood volume with changes in position in awake and anesthetized subjects. Anesth. Analg. 90: 372-376.

13. Magnaes, B. 1976. Body position and cerebrospinal fluid pressure. Part 1: Clinical studies on the effect of rapid postural changes. J. Neurosurg. 44: 687-697.

14. Mori, Y., Takeuchi, Y., Shimada, M., Hayashi, S. and Hoshino, K. 1990. Stereotaxic approach to hypothalamic nuclei of the Shiba goat with radiographic monitoring. J. Vet. Med. Sci. 52: 339-349.

15. Rings, D. M. and Muir, W. W. 1982. Cardiopulmonary effects of intramuscular xylazine-ketamine in calves. Can. J. Comp. Med. 46: 386-389.

16. Rugh, K. S., Zinn, G. M., Paterson, J. A. and Thorne J. G. 1985. Inhalation anesthesia in adult cattle. Lab. Anim. Sci. 35: 
178-181.

17. Semrad, S. D., Trim, C. M. and Hardee G. E. 1986. Hypertension in bulls and steers anesthetized with guaifenesin-thiobarbiturate-halothane combination. Am. J. Vet. Res. 47: 15771583.

18. Shah, J. L., 1984. Effect of posture on extradural pressure. $B r$. J. Anaesth. 56: 1373-1377.

19. Shiogai, T., Nara, I., Saruta, K., Hara, M. and Saito, I. 1999. Continuous monitoring of cerebrospinal fluid acid-base balance and oxygen metabolism in patients with severe head injury: pathophysiology and treatments for cerebral acidosis and Ischemia. Acta Neurochir. 75: 49-55.

20. Sorenson, P. R. and Robinson, N. E. 1980. Postural effects on lung volumes and asynchronous ventilation in anesthetized horses. J. Appl. Physiol. 48: 97-103.

21. Tagawa, M., Okano, S., Sako, T., Orima, H. and Steffey, E. P. 1994. Effect of change in body position, cardiopulmonary function and plasma cortisol in cattle. J. Vet. Med. Sci. 56: 131-134.

22. Takakura, K. 1993. Monitoring of intracranial pressure. pp. 163-180. In: Essentials of Monitoring in Neurosurgery, Gendaiiryousha, Tokyo (in Japanese).

23. Tsuka, T., Taura, Y., Okamura, S., Nakaichi, M., Une, S. and Hayashi, T. 2001. Diagnoses of bovine brain diseases using permanent magnetic response imaging. J. Jpn. Vet. Med. Assoc. 54: 265-268.

24. Xiao-feng, Y., Wei-guo, L., Hong, S., Jiang-biao, G., Jun, Y., Wei-wei, H., Shi-ting, L., Xiu-jue, Z. and Wei-ming, F. 2005. Correlation of cell apoptosis with brain edema and elevated intracranial pressure in traumatic brain injury. Chin. J. Traumatol. 8: 96-100.

25. Zuccolilli, G. O. and Mori, Y. 1995. Cranial and cerebro-ventricular landmarks for accurate stereotaxic approach to hypothalamic nuclei in the goat brain. J. Vet. Med. Sci. 57: 453-457. 